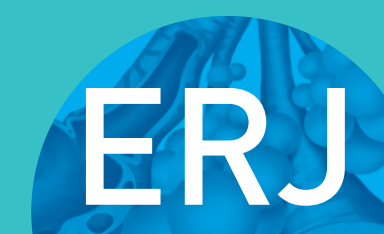

open research

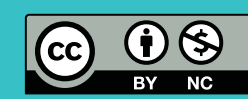

\section{Dynamic hyperinflation during the 6-min walk test in severely asthmatic subjects}

\author{
Alida Benfante ${ }^{1,3}$, Fabiano Di Marco ${ }^{2,3}$, Silvia Terraneo ${ }^{2}$, Stefano Centanni ${ }^{2}$ and \\ Nicola Scichilone ${ }^{1}$
}

Affiliations: ${ }^{1}$ Dipartimento Biomedico di Medicina Interna e Specialistica, Sezione di Pneumologia, University of Palermo, Palermo, Italy. ${ }^{2}$ Respiratory Unit, Ospedale San Paolo, ASST Santi Paolo e Carlo, Dept of Health Sciences, Università degli Studi di Milano, Milan, Italy. ${ }^{3}$ These two authors contributed equally to this work.

Correspondence: Nicola Scichilone, Dipartimento di Biomedicina e Medicina Specialistica, Sezione di Pneumologia, University of Palermo, Via Trabucco 180, 90146 Palermo, Italy. E-mail: nicola.scichilonedunipa.it

ABSTRACT We tested the hypothesis that dynamic hyperinflation develops in severe asthmatic subjects during exercise. Changes in inspiratory capacity (IC) were measured during the 6-min walk test (6MWT) in severe asthmatic subjects compared with chronic obstructive pulmonary disease (COPD) subjects with a similar degree of bronchial obstruction. We assessed whether changes in IC were associated with changes in dyspnoea perception.

27 severe asthmatic subjects (10 males and 17 females) and 43 COPD subjects (35 males and eight females) were recruited. The two groups performed similarly in the $6 \mathrm{MWT}(\mathrm{p}=0.90)$. At the end of the test, the Borg score increased significantly in both groups (mean difference: for asthmatic subjects $1.7 \pm 1.6$; $\mathrm{p}<0.0001$; for COPD subjects $3.1 \pm 1.9 ; \mathrm{p}<0.0001$ ). IC measured at the beginning of $6 \mathrm{MWT}$ was not different between groups $(2.25 \pm 0.47 \mathrm{~L}$ in asthmatic subjects versus $2.38 \pm 0.60 \mathrm{~L}$ in COPD subjects; $\mathrm{p}=0.32)$ and decreased in both groups (mean difference: for asthmatic subjects $0.160 \mathrm{~L} ; \mathrm{p}=0.02$; for COPD subjects $0.164 \mathrm{~L} ; \mathrm{p}<0.0001)$. However, changes in IC were significantly associated with changes in the Borg score in the COPD group $\left(\mathrm{r}^{2}=0.17 ; \mathrm{p}=0.006\right)$, but not in the asthma group $\left(\mathrm{r}^{2}=0.06 ; \mathrm{p}=0.20\right)$.

In severe asthmatic subjects, IC significantly drops during the 6MWT to the same extent as COPD subjects with a similar degree of lung impairment, indicating the development of dynamic hyperinflation. Contrary to COPD, in asthmatic subjects the occurrence of dynamic hyperinflation was not associated with changes in dyspnoea perception.

@ERSpublications

Severe asthma is characterised by occurrence of dynamic hyperinflation during exercise; inspiratory capacity drops in severe asthmatic subjects during the 6MWT to the same extent as in COPD subjects with similar lung impairment http://ow.ly/InfQ30jjivW

Cite this article as: Benfante A, Di Marco F, Terraneo S, et al. Dynamic hyperinflation during the 6-min walk test in severely asthmatic subjects. ERJ Open Res 2018; 4: 00143-2017 [https://doi.org/ 10.1183/23120541.00143-2017].

Received: Nov 092017 | Accepted after revision: March 282018

Copyright $\odot$ ERS 2018. This article is open access and distributed under the terms of the Creative Commons Attribution Non-Commercial Licence 4.0. 


\section{Introduction}

Asthma is a common disease worldwide, impacting on daily activities and quality of life, especially in its most severe forms [1, 2]. Indeed, dyspnoea on exertion is the most cited and troublesome symptom described by uncontrolled asthmatic patients, mainly for inspiratory effort and not rarely for the occurrence of dynamic hyperinflation [3,4]. Dynamic hyperinflation is considered the underlying mechanism of exertional dyspnoea in subjects with chronic obstructive pulmonary disease (COPD) and the main cause of disability in these patients. O'Donnell [5] demonstrated that the occurrence of dynamic hyperinflation during exercise in COPD strongly correlates with dyspnoea perception. Although dynamic hyperinflation is recognised as a key determinant of exercise limitation in COPD, little is known about this in other respiratory chronic conditions, such as bronchial asthma [6]. In COPD, the end-expiratory lung volume increases because of airflow limitation, usually due to the increase of ventilation during exercise, and it is expressed as a decrease in inspiratory capacity (IC). Therefore, changes in IC can be regarded as a useful marker of dynamic hyperinflation under experimental conditions that resemble those of daily life. It is plausible to speculate that, in asthma, the state of chronic airway inflammation could lead to oedema and airway smooth muscle contraction that, in turn, are responsible for the small airway collapse and airflow limitation leading to dynamic hyperinflation. Moreover, dynamic hyperinflation can also exert pro-inflammatory effects, mainly through a cellular stretch that acts as a potent inflammatory stimulus [7]. In a study conducted on 22 mild to moderate asthmatic subjects, LAVENEZIANA et al. [8] recorded the occurrence of dynamic hyperinflation during a short cardiopulmonary exercise test in a subgroup of subjects. SATAKE et al. [9] found that IC decreased after the 6-min walk test (6MWT) in 23 stable COPD subjects and negatively correlated with dyspnoea.

We speculate that the most severe forms of asthma may be characterised by the occurrence of dynamic hyperinflation during exercise. To this aim, we assessed changes in IC during the 6MWT in severe asthmatic subjects and established whether these changes are associated with dyspnoea. COPD subjects, matched for degree of bronchial obstruction, served as a control group.

\section{Methods}

This was a case-control study carried out at the Respiratory Units of the University of Palermo (Palermo, Italy) and the San Paolo Hospital, University of Milan (Milan, Italy). Local ethics committees approved the study and written consent was obtained from each participant.

\section{Study population}

We enrolled two groups of subjects: 1) consecutive outpatients suffering from severe asthma, according to the European Respiratory Society (ERS) statement [1], and 2) consecutive patients with COPD diagnosis according to American Thoracic Society (ATS)/ERS guidelines [10] (i.e. post-bronchodilator forced expiratory volume in $1 \mathrm{~s}$ (FEV1)/forced vital capacity below the lower limit of normal) attending scheduled follow-up consultation with $\mathrm{FEV}_{1}>50 \%$ of predicted, matched for the same degree of bronchial obstruction. Exclusion criteria were: relevant contraindications to clinical exercise testing, exacerbations within the last 4 weeks, comorbidities that could affect exercise capacity, treatment with $\beta$-blockers and inability to perform the study protocol.

\section{Study design}

All subjects underwent careful medical history evaluation and symptoms assessment. Asthma control was established by the Asthma Control Test (ACT), which was self-administered. The ACT is a validated five-item instrument, each item rated on a five-point scale, providing a total score that allows discrimination between "well-controlled" (total score 25), "partially controlled" (total score 20-<25) and "not controlled" (total score <20). The questions address symptoms occurring within the 4 weeks preceding the evaluation. The frequency of exacerbations in the previous year was also recorded.

Dyspnoea was measured using the Italian version of the modified Medical Research Council dyspnoea scale. Then, patients performed forced and slow vital capacity manoeuvres in accordance with ATS/ERS guidelines $[11,12]$. The $6 \mathrm{MWT}$ was performed along a flat, straight, 30-m walking course supervised by a well-trained researcher according to ATS guidelines [13], using a portable spirometer (Spiropalm; COSMED, Rome, Italy) with integrated pulse oximeter and ventilation measurement, which allows the measurement of IC at the beginning (at resting conditions) and immediately after the end of the test [14]. Exercise breathlessness was graded using the Borg scale [15]. Dynamic hyperinflation was defined as a decrease of $>150 \mathrm{~mL}$ in IC at the end of exercise compared with resting levels [16].

\section{Statistical analysis}

The results are expressed as mean and standard deviation, unless otherwise stated. This was a pilot study. In view of the lack of previous experiences, no formal sample size calculation was made. Before data 
analysis, Lilliefors corrected Kolmogorov-Smirnov test was performed to examine the distribution of the residuals of the parametric tests. Quantitative variables were analysed using the t-test or Mann-Whitney test as appropriate. All tests were two-sided and p-values $<0.05$ were considered statistically significant. Statistical tests were performed using SPSS version 21.0 (IBM, Armonk, NY, USA).

\section{Results}

27 patients with severe asthma ( 10 males and 17 females) and 43 individuals affected by COPD ( 35 males and eight females) were recruited while in stable condition. All study subjects were under optimal inhaled treatment according to the stage of the disease, which was not stopped on the day of the study. All asthmatic subjects were under high-dose inhaled corticosteroids plus long-acting $\beta_{2}$-adrenergics. COPD subjects were taking long-acting $\beta_{2}$-adrenergics and/or long-acting muscarinic antagonists, together with inhaled corticosteroids according to the severity of their disease. None of the study subjects was under systemic corticosteroid treatment or biological drugs at the time of enrolment. No significant comorbid conditions potentially affecting the outcomes of the study (i.e. cognitive impairment, nonrespiratory mobility difficulties, heart failure) were documented. Asthmatic subjects were significantly younger than COPD subjects $(57 \pm 11$ versus $66 \pm 10$ years, respectively; $\mathrm{p}=0.002)$. Body mass index did not differ between the two groups (28.6 \pm 5.0 versus $27.2 \pm 4.1 \mathrm{~kg} \cdot \mathrm{m}^{-2}$, respectively; $\left.\mathrm{p}=0.19\right)$. Among asthmatic subjects, 18 subjects had never smoked, two were current smokers and seven were ex-smokers; conversely, among COPD subjects, only one had never smoked, 23 were current smokers and 19 were ex-smokers. Lung function characteristics are depicted in table 1. By design, the degree of airway obstruction was similar between groups. For asthmatic subjects, the mean ACT score was $16 \pm 3$ and the rate of exacerbations in the previous year was $1.2 \pm 0.6$. In COPD subjects, the rate of exacerbations was $2.2 \pm 0.8$.

The two groups did not differ in terms of metres walked in the 6MWT (asthmatic subjects versus COPD subjects: $392 \pm 71$ versus $389 \pm 97 \mathrm{~m}$; $\mathrm{p}=0.90$ ). Heart rate at the beginning of the test was $84 \pm 14$ beats $\cdot \mathrm{min}^{-1}$ in the asthmatic subjects and $66 \pm 43$ beats $\mathrm{min}^{-1}$ in the COPD subjects $(\mathrm{p}=0.03)$. In both groups, the heart rate reached a peak value during the test that was significantly higher than baseline (mean difference: for asthmatic subjects $25 \pm 18$ beats $\mathrm{min}^{-1}$; $\mathrm{p}<0.0001$; for COPD subjects $22 \pm 19$ beats $\mathrm{min}^{-1}$; $\mathrm{p}<0.0001$ ). Minute ventilation at the beginning of the $6 \mathrm{MWT}$ was $13.5 \pm 7.3 \mathrm{~L} \cdot \mathrm{min}^{-1}$ in asthmatic subjects and $4.3 \pm 6.7 \mathrm{~L} \cdot \mathrm{min}^{-1}$ in COPD subjects, and reached a significantly higher peak value in both groups (mean difference: for asthmatic subjects $18 \mathrm{~L} \cdot \mathrm{min}^{-1}$; $\mathrm{p}<0.0001$; for COPD subjects $23 \mathrm{~L} \cdot \mathrm{min}^{-1}$; $\mathrm{p}<0.0001$ ). Percutaneous oxygen saturation at the beginning of the test was $95 \pm 2 \%$ in asthmatic subjects and $96 \pm 3 \%$ in COPD subjects $(p=0.26)$, and remained unchanged at the end of the test in the asthmatic subjects (mean difference $0.26 \%$; $\mathrm{p}=0.56$ ), whereas it dropped significantly in the COPD subjects (mean difference $2.0 \% ; \mathrm{p}<0.0001$ ). The Borg score was significantly different between the two groups prior to the procedure (asthmatic subjects versus COPD subjects: $1.1 \pm 1.3$ versus $0.3 \pm 0.8 ; \mathrm{p}=0.002$ ). At the end of the test, the Borg score increased significantly in both groups (mean difference: for asthmatic subjects $1.7 \pm 1.6 ; \mathrm{p}<0.0001$; for COPD subjects $3.1 \pm 1.9 ; \mathrm{p}<0.0001)$.

The IC measured at the beginning of the $6 \mathrm{MWT}$ was not different between groups $(2.25 \pm 0.47 \mathrm{~L}$ in asthmatic subjects versus $2.38 \pm 0.60 \mathrm{~L}$ in COPD subjects; $\mathrm{p}=0.32$ ). During the test, IC significantly decreased in both groups by the same extent (mean difference: for asthmatic subjects $0.160 \mathrm{~L}$; $\mathrm{p}=0.02$; for COPD subjects $0.164 \mathrm{~L} ; \mathrm{p}<0.0001$ ) (figure 1 ). Interestingly, changes in IC were significantly associated with changes in the Borg score in the COPD group $\left(\mathrm{r}^{2}=0.17 ; \mathrm{p}=0.006\right)$, but not in the asthmatic group $\left(\mathrm{r}^{2}=0.06\right.$;

\section{TABLE 1 Baseline lung functional characteristics of the study subjects}

\begin{tabular}{lccc} 
& Severe asthmatic subjects & COPD subjects & p-value \\
\hline FEV 1 \% pred & $74 \pm 22$ & $73 \pm 22$ & 0.89 \\
FVC \% pred & $89 \pm 19$ & $92 \pm 22$ & 0.57 \\
FEV 1 FVC & $0.68 \pm 0.1$ & $0.62 \pm 0.1$ & 0.02 \\
FEF25-75\% \% pred & $40 \pm 21$ & $35 \pm 16$ & 0.23 \\
FEF75\% \% pred & $53 \pm 24$ & $33 \pm 19$ & 0.0007 \\
FEF50\% \% pred & $41 \pm 22$ & $38 \pm 20$ & 0.57 \\
FEF25\% \% pred & $37 \pm 21$ & $47 \pm 23$ & 0.10
\end{tabular}

Data are presented as mean $\pm \mathrm{SD}$, unless otherwise stated. COPD: chronic obstructive pulmonary disease; FEV1: forced expiratory volume in $1 \mathrm{~s}$; FVC: forced vital capacity; FEF: forced expiratory flow; FEF25-75\%: FEF at $25-75 \%$ of FVC; FEF $75 \%$ : FEF at $75 \%$ of FVC; FEF50\%: FEF at $50 \%$ of FVC; $F E F 25 \%$ : FEF at $25 \%$ of FVC. 
FIGURE 1 Changes in inspiratory capacity (IC) during the 6-min walk test. COPD: chronic obstructive pulmonary disease. $p<0.0001$ for both groups.

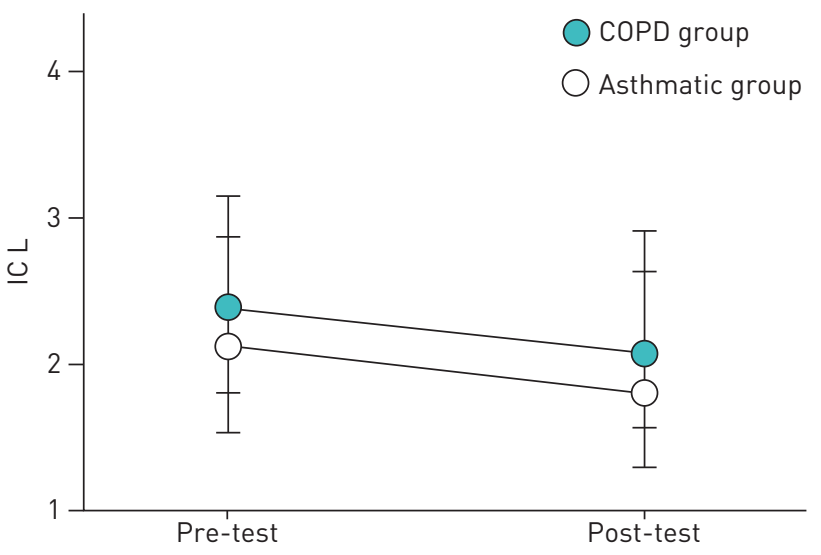

$\mathrm{p}=0.20$ ) (figure $2 \mathrm{a}$ and $\mathrm{b}$ ). The changes in IC during the $6 \mathrm{MWT}$ were not predicted by the degree of airway obstruction (FEV1 \% pred) in either group ( $\mathrm{p}>0.05)$.

\section{Discussion}

The current study was designed to test the hypothesis that the most severe forms of asthma are characterised by the occurrence of dynamic hyperinflation during exercise. By using a portable system, we found that during the 6MWT IC significantly decreased in severe asthmatic subjects and this reduction did not differ from that observed in COPD subjects with a similar magnitude of airway obstruction. The lack of association between changes in IC and in dyspnoea perception in severe asthmatic subjects as opposed to COPD subjects suggests that in the former exertional dyspnoea has multiple determinants.

Tidal expiratory flow limitation (EFL) is a pathophysiological feature of COPD, and arises because of the dual effects of permanent parenchymal destruction and airway obstruction [17]. In COPD patients, the increased compliance of the lung leads to a resetting of the respiratory system's relaxation volume to a higher level than in age-matched healthy individuals and this phenomenon is termed static lung hyperinflation. The EFL occurs in a significant proportion of patients with COPD during resting breathing and in almost all COPD patients during exercise [18], resulting in dynamic hyperinflation that is reflected in decreased IC and associated with impaired exercise performance [18-20]. O'DonNelL et al. [16] examined dynamic hyperinflation during exercise in COPD and healthy age-matched controls, and concluded that inability to expand tidal volume in response to increasing metabolic demand contributed importantly to exercise intolerance in COPD. MARIN et al. [21] tested the hypothesis that dyspnoea during the 6MWT could be associated with the development of dynamic hyperinflation. As most clinicians evaluate their patients with questions that relate breathlessness to activities of daily living such as walking, the 6MWT has become a popular, reliable and safe alternative to the more formal cardiopulmonary exercise test [22], and correlates with treadmill exercise [23]. MARIN et al. [21] measured IC at rest and after a 6MWT in 72 males with COPD, showing that simple walking results in dynamic hyperinflation that can be easily determined using IC and that the increased perception of dyspnoea during walking
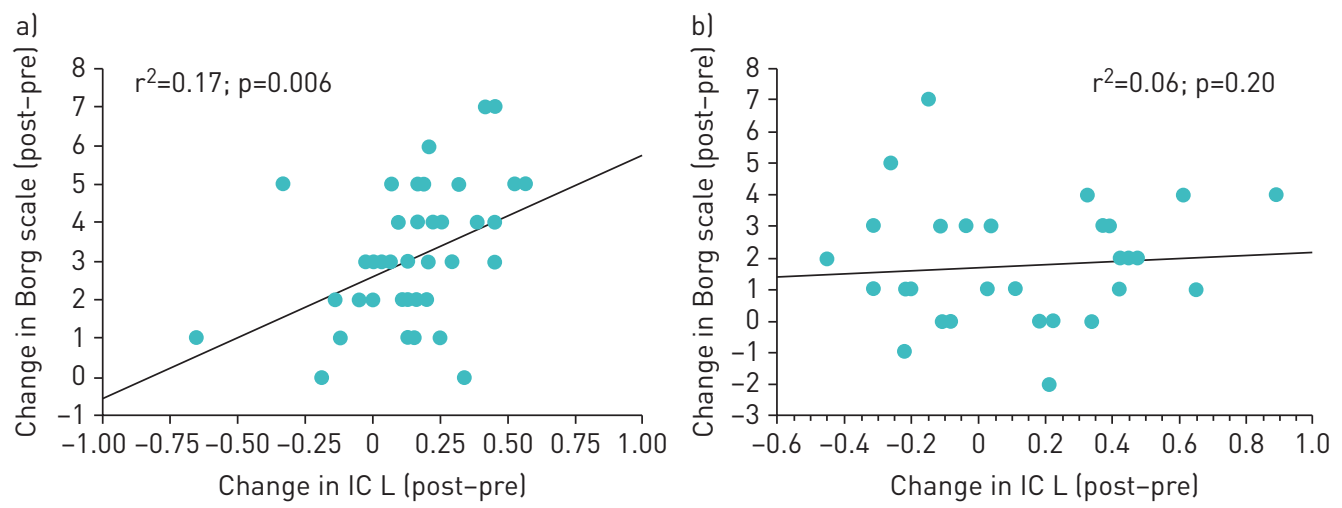

FIGURE 2 Association between changes in inspiratory capacity (IC) during the 6-min walk test and changes in the Borg scale: a) chronic obstructive pulmonary disease group and b) asthmatic group. 
correlates with the degree of dynamic hyperinflation. These findings were confirmed in a recent study by SATAKE et al. [9] performed in 23 subjects with stable COPD and replicated in our COPD group. Interestingly, OfiR et al. [24] showed that dynamic hyperinflation also develops during exercise tests in symptomatic patients with mild COPD and relatively preserved lung function, together with dyspnoea increase and exercise curtailment.

The current finding of the occurrence of dynamic hyperinflation during exercise in severe asthmatic subjects is novel and could contribute to explain exertional dyspnoea in this population. A clear relationship between activity limitation and quality of life has been demonstrated in asthmatic subjects. Uncontrolled asthma is associated with a two-fold risk of limitation of physical activity with a negative impact on work and regular activities [3,4]. Several mechanisms are responsible for activity limitation in asthma, such as peripheral and respiratory muscle impairments and the negative impact of systemic corticosteroids [6]. Respiratory function, exercise capacity (6MWT distance, incremental cycloergometry and inspiratory threshold loading) and dyspnoea were assessed in seven patients with a history of near-fatal asthma and eight non-near-fatal asthma patients [25]. Although exercise tolerance was similarly reduced in both the near-fatal asthma and non-near-fatal asthma groups, dyspnoea at peak cycle exercise was significantly lower in the former who mainly stopped because of leg discomfort. A similar trend was observed in the 6MWT and inspiratory threshold loading test. However, few data are available with regard to EFL and dynamic hyperinflation during exercise. In their study, BARREIRO et al. [25] found that patients with a history of near-fatal asthma had a significant decrease in IC during cardiopulmonary exercise testing (CPET). Dynamic hyperinflation is known to induce an intrinsic positive end-expiratory alveolar pressure, acting as a threshold inspiratory load and causing the tidal volume to set in a stiffer portion of the volume-pressure curve, thus increasing the elastic load, and leading to increased mechanical impedance of the respiratory system on inspiratory muscles that are functionally weaker, mainly because of an unfavourable position on their length-tension curve [26, 27]. It has been demonstrated that stable asthmatic patients seldom exhibit EFL during resting breathing [28, 29], unless under severe and prolonged bronchoconstriction [30]. LAVENEZIANA et al. [8] assessed IC and the perception of dyspnoea in 22 stable asthmatic patients during short CPET and methacholine inhalation. Airway obstruction and hyperinflation were the best predictors of dyspnoea during methacholine challenge, whereas work rate, minute ventilation and tidal volume were the best predictors of dyspnoea in subjects undergoing CPET.

Our findings show that the Borg score at rest was significantly higher in COPD subjects than in asthmatic subjects, although matched for airway obstruction, as already found in previous studies [31-33]. In addition, similar to previous studies [31-33], changes in the Borg score during exercise were relatively low in the asthmatic populations. It was hypothesised that this may be related to the fact that the highest score on the Borg scale is anchored to the most severe breathlessness that patients had ever experienced [33]. Thus, since, unlike other patients, most asthmatic subjects experience severe breathlessness only during acute episodes of bronchoconstriction, they may perceive a relatively low sensation of dyspnoea during exercise. Interestingly, our investigation failed to find a significant relationship between changes in IC and in Borg scores, as opposed to COPD. This challenges our hypothesis of dynamic hyperinflation being the most relevant determinant of exertional dyspnoea in asthmatic subjects and suggests that other mechanisms, such as a mismatch between central drive and respiratory movements or different qualitative sensations of dyspnoea, could be implicated to explain the occurrence of dyspnoea during exercise.

The mechanisms leading to airflow limitation and dynamic hyperinflation in asthma may differ from the well-known pathogenetic factors that are implicated in COPD. AGUsTi et al. [7] speculated about the potential relationships between dynamic hyperinflation and airway inflammation. Inflammation contributes to the pathogenesis of dynamic hyperinflation through the oedema and increased airway resistance, increased mucus production and alveolar destruction. It is plausible to speculate that inflammation at the level of peripheral airways in asthma is responsible for the occurrence of EFL and dynamic hyperinflation. In this respect, a body of evidence has accumulated to confirm that small airways are the major site of inflammation in severe asthmatic subjects [34, 35], and features of air trapping and lung hyperinflation characterise the most severe forms of asthma [36-39]. The observation of loss of alveolar attachments in fatal asthma [40], as well as loss of elastic recoil and reduced diffusing capacity in severe asthmatic subjects [41], could imply the involvement of the parenchymal component of the lung, which deserves to be investigated in specifically designed studies. Of note, dynamic hyperinflation could contribute to inflammation, thus perpetuating the functional abnormalities; dynamic hyperinflation has been shown to promote pro-inflammatory effects through several mechanisms: cellular stretching, tissue damage and danger signals, and hyperventilation and hypoxia.

The study has some limitations. First, as the study was not designed to explore the mechanisms of dyspnoea on exertion in asthmatic subjects, the explanations provided are only speculative and not persuasive. Second, it is possible that some patients in both groups were not stressed enough during the 
walking test to induce severe dyspnoea ( $<2$-unit increase in Borg ratings during the 6MWT), thus potentially limiting the results. If any, however, we would expect dynamic hyperinflation to occur earlier and to correlate with changes in dyspnoea with more intensive exercise. Third, little is known on the individual level about daily activities and conditioning, which could have potentially affected the differences between groups. Finally, enrolled asthmatic patients were significantly younger than those with COPD, with fewer comorbidities. This aspect could theoretically affect the occurrence of dynamic hyperinflation, which has been demonstrated in other conditions such as chronic heart failure. However, patients with comorbidities that could affect exercise capacity had been excluded, thus reasonably ruling out this bias.

In conclusion, the current study showed that severe asthmatic subjects develop dynamic hyperinflation during exercise to the same magnitude as COPD subjects. This phenomenon could add some insight into the mechanism of daily exercise limitations in this population. Further studies are needed to explore the determinants of exertional dyspnoea in severe asthmatic subjects.

Author contributions: A. Benfante participated in the design of the study, recruited the patients, performed the study tests, collected and analysed the data, and contributed to the writing of the manuscript. F. Di Marco participated in the design of the study, analysed the data, and participated in the interpretation of the results and the writing of the manuscript. S. Terraneo recruited the patients, performed the study tests, and collected and analysed the data. S. Centanni contributed to the interpretation of the results and to the writing of the manuscript. N. Scichilone conceived and designed the study, recruited the patients, participated in the analysis of the data, and wrote the first version of the manuscript. He is the guarantor of the paper.

Conflict of interest: None declared.

Support statement: The University of Palermo and University of Milan supported the study. The investigation had no external funding from other agencies. Funding information for this article has been deposited with the Crossref Funder Registry.

\section{References}

1 Chung KF, Wenzel SE, Brozek JL, et al. International ERS/ATS guidelines on definition, evaluation and treatment of severe asthma. Eur Respir J 2014; 43: 343-373.

2 Wilson SR, Rand CS, Cabana MD, et al. Asthma outcomes: quality of life. J Allergy Clin Immunol 2012; 129: 88-123.

3 Miller DP, Haselkorn R, Fish JE, et al. Asthma control and activity limitations: insight from the real-world evaluation of asthma control and treatment (REACT) study. Ann Allergy Asthma Immunol 2010; 104: 471-477.

4 Pollack M, Wertz DA, Rodgers K, et al. Impact of asthma control on sleep, attendance at work, normal activities, and disease burden. Ann Allergy Asthma Immunol 2010; 105: 118-123.

5 O'Donnell DE. Breathlessness in patients with chronic airflow limitation. Mechanisms and management. Chest 1994; 106: 904-912.

6 Vermeulen F, Garcia G, Ninane V, et al. Activity limitation and exertional dyspnea in adult asthmatic patients: what do we know? Respir Med 2016; 117: 122-130.

7 Agusti A, Soriano JB. Dynamic hyperinflation and pulmonary inflammation: a potentially relevant relationship? Eur Respir Rev 2006; 15: 68-71.

8 Laveneziana P, Lotti P, Coli C, et al. Mechanisms of dyspnea and its language in patients with asthma. Eur Respir J 2006; 27: 742-747.

9 Satake M, Shioya T, Uemura S, et al. Dynamic hyperinflation and dyspnea during the 6-minute walk test in stable chronic obstructive pulmonary disease patients. Int J Chron Obstruct Pulmon Dis 2015; 10: 153-158.

10 Qaseem A, Wilt TJ, Weinberger SE, et al. Diagnosis and management of stable chronic obstructive pulmonary disease: a clinical practice guideline from the American College of Physicians, American College of Chest Physicians, American Thoracic Society, and European Respiratory Society (2011). Ann Intern Med 2011; 155: $179-191$.

11 Miller MR, Hankinson J, Brusasco V, et al. Standardisation of spirometry. Eur Respir J 2005: 26: 319-338.

12 Wanger J, Clausen JL, Coates A, et al. Standardisation of the measurement of lung volumes. Eur Respir J 2005: 26: 511-522.

13 Callens E, Graba S, Gillet-Juvin K, et al. Measurement of dynamic hyperinflation after a 6-minute walk test in patients with COPD. Chest 2009; 136: 1466-1472.

14 ATS Committee on Proficiency Standards for Clinical Pulmonary Function Laboratories. ATS statement: guidelines for the six-minute walk test. Am J Respir Crit Care Med 2002; 166: 111-117.

15 Borg G. Subjective effort and physical abilities. Scand J Rehabil Med Suppl 1978; 6: 105-113.

16 O'Donnell DE, Revill SM, Webb KA. Dynamic hyperinflation and exercise intolerance in chronic obstructive pulmonary disease. Am J Respir Crit Care Med 2001: 164: 770-777.

17 O'Donnell DE, Laveneziana P. Physiology and consequences of lung hyperinflation in COPD. Eur Respir Rev 2006; 15: 61-67.

18 Koulouris NG, Dimopoulou I, Valta P, et al. Detection of expiratory flow limitation during exercise in COPD patients. J Appl Physiol 1997; 82: 723-731.

19 Diaz O, Villafranca C, Ghezzo H, et al. Role of inspiratory capacity on exercise tolerance in COPD patients with and without tidal expiratory flow limitation at rest. Eur Respir J 2000; 16: 269-275.

20 Diaz O, Villafranca $\mathrm{C}$, Ghezzo $\mathrm{H}$, et al. Breathing pattern and gas exchange at peak exercise in COPD patients with and without tidal flow limitation at rest. Eur Respir J 2001; 17: 1120-1127. 
21 Marin JM, Carrizo SJ, Gascon M, et al. Inspiratory capacity, dynamic hyperinflation, breathlessness, and exercise performance during the 6-minute-walk test in chronic obstructive pulmonary disease. Am J Respir Crit Care Med 2001; 163: 1395-1399.

22 Redelmeir DA, Bayoumi AM, Goldstein DS, et al. Interpreting small differences in functional status: the six minute walk test in chronic lung diseases patients. Am J Respir Crit Care Med 1997; 155: 1278-1282.

23 Stevens D, Elpern E, Sharma K, et al. Comparison of hallway and treadmill six-minute walk test. Am J Respir Crit Care Med 1999; 160: 1540-1543.

24 Ofir D, Laveneziana P, Webb KA, et al. Mechanisms of dyspnea during cycle exercise in symptomatic patients with GOLD stage I chronic obstructive pulmonary disease. Am J Respir Crit Care Med 2008; 177: 622-629.

25 Barreiro E, Gea J, Sanjuas C, et al. Dyspnea at rest and at the end of different exercises in patients with near-fatal asthma. Eur Respir J 2004; 24: 219-225.

26 Pepe AE, Marini JJ. Occult positive end-expiratory pressure in mechanically ventilated patients with airflow obstruction: the auto-PEEP effect. Am Rev Respir Dis 1982; 26: 166-170.

27 Boni E, Corda L, Franchini D, et al. Volume effect and exertional dyspnea after bronchodilator in patients with COPD with and without expiratory flow limitation at rest. Thorax 2002; 57: 528-532.

28 Boczkowski J, Murciano D, Pichot MH, et al. Expiratory flow limitation in stable asthmatic patients during resting breathing. Am J Respir Crit Care Med 1997; 156: 752-757.

29 Baydur A, Milic-Emili J. Expiratory flow limitation during spontaneous breathing: comparison of patients with restrictive and obstructive respiratory disorders. Chest 1997; 112: 1017-1023.

30 Tantucci C, Ellaffi M, Duguet A, et al. Dynamic hyperinflation and flow limitation during methacholine-induced bronchoconstriction in asthma. Eur Respir J 1999; 14: 295-301.

31 Banzett RB, Dempsey JA, O’Donnell DE, et al. Symptom perception and respiratory sensation in asthma. Am J Respir Crit Care Med 2000; 162: 1178-1182.

32 Killian KJ, Summers E, Watson RM, et al. Factors contributing to dyspnea during bronchoconstriction and exercise in asthmatic subjects. Eur Respir J 1993; 6: 1004-1010.

33 Kosmas EN, Milic-Emili J, Polychronaki A, et al. Exercise-induced flow limitation, dynamic hyperinflation and exercise capacity in patients with bronchial asthma. Eur Respir J 2004; 24: 378-384.

34 Hamid Q, Song Y, Kotsimbos TC, et al. Inflammation of small airways in asthma. J Allergy Clin Immunol 1997; 100: 44-51.

35 Burgel PR, de Blic J, Chanez P, et al. Update on the roles of distal airways in asthma. Eur Respir Rev 2009; 18: 80-95.

36 Wenzel S. Severe asthma in adult. Am J Respir Crit Care Med 2005; 172: 149-160.

37 The ENFUMOSA Study Group. The ENFUMOSA cross-sectional European multicentre study of the clinical phenotype of chronic severe asthma. Eur Respir J 2003; 22: 470-477.

38 Jarjour NN, Erzurum SC, Bleecker ER, et al. Severe asthma: lessons learned from the National Heart, Lung, and Blood Institute Severe Asthma Research Program. Am J Respir Crit Care Med 2012; 185: 356-362.

39 Busacker A, Newell JD Jr, Keefe T, et al. A multivariate analysis of risk factors for the air-trapping asthmatic phenotype as measured by quantitative CT analysis. Chest 2009; 135: 48-56.

40 Mauad T, Silva LF, Santos MA, et al. Abnormal alveolar attachments with decreased elastic fiber content in distal lung in fatal asthma. Am J Respir Crit Care Med 2004; 170: 857-862.

41 Gelb AF, Zamel N, Hogg JC, et al. Pseudophysiologic emphysema resulting from severe small-airways disease. Am J Respir Crit Care Med 1998; 158: 815-819. 